\title{
QUESTÕES ONTO-EPISTÊMICAS E EDUCAÇÃO EM CIÊNCIAS: REFLEXÕES A PARTIR DE JUDITH BUTLER E ANÍBAL QUIJANO
}

\section{HiATA ANDERSON SILVA dO NASCIMENTO}

Instituto Federal do Espírito Santo

Email: hiata.nascimento@ifes.edu.br

\section{BRUNO ANDRADE PINTO MONTEIRO}

Instituto Nutes

Email: bpmonteiro@gmail.com

\begin{abstract}
RESUMO
O artigo relaciona as obras de Aníbal Quijano e Judith Butler, como centrais chaves para pensarmos alguns desafios onto-epistemológicos colocados à Educação em Ciências. Selecionamos para análise os conceitos de "Colonialidade" (Quijano) e "Marcos de Inteligibilidade" e "Precariedade" (Butler), instigados por algumas questões: De que modo esses conceitos se articulam? É possível encontrarmos pontos de convergência entre ambos de forma que possamos pensar a promoção do direito de ser e de saber na Educação em Ciências? O texto incorpora uma pesquisa bibliográfica, a partir de dois momentos: a) análise teórico-metodológica das abordagens dos autores citados; b) uma discussão sobre o modo como eles se articulam a partir da análise de três obras que tratam da decolonialidade na Educação em Ciências. O material é interpretado a partir das discussões realizadas no campo das Ciências Sociais e da Educação em Ciências e que visam pensar as condições de produção do conhecimento científico.
\end{abstract}

\section{PALAVRAS-CHAVE:}

Aníbal Quijano; Judith Butler; epistemologia; Educação em Ciências; decolonialidade.

ONTO-EPISTEMIC QUESTIONS AND SCIENCE EDUCATION: REFLECTIONS FROM JUDITH BUTLER AND ANÍBAL QUIJANO

\begin{abstract}
The paper lists the works of Aníbal Quijano and Judith Butler, as keys to thinking about some ontoepistemological challenges put to Science Education. We selected for analysis the concepts of "Coloniality" (Quijano) and "Schemas of Intelligibility" and "Precariousness" (Butler), instigated by some questions: How are these concepts articulated? Is it possible to find points of convergence between both so that we can think about promoting the right to be and to know in Science Education? The text incorporates a bibliographic research, starting from two moments: a) theoreticalmethodological analysis of the approaches of the authors mentioned; b) a discussion on the way they articulate themselves from the analysis of three books that deal with decoloniality in Science Education. The material is interpreted from the discussions held in the Social Sciences and Science Education and which aim to think about the conditions for the production of scientific knowledge.
\end{abstract}

\section{KEYWORDS:}


Aníbal Quijano; Judith Butler; epistemology; Science Education; decoloniality.

\section{INTRODUÇÃO}

O objetivo deste artigo é relacionar a obra do sociólogo peruano Aníbal Quijano com a perspectiva da filósofa estadunidense Judith Butler, como centrais para pensarmos alguns desafios ontológicos e epistemológicos colocados ao campo da Educação em Ciências. Tomamos como ponto de referência, para melhor circunscrição e análise, os conceitos de "colonialidade do poder", elaborado por Quijano, e "marcos de inteligibilidade" e "precariedade", construídos por Butler, instigados por algumas questões: De que modo esses conceitos se articulam? É possível encontrarmos pontos de convergência entre ambos de forma que possamos pensar a promoção do direito de ser e de saber no contexto da Educação em Ciências? Como esse direito de ser e de saber tem sido historicamente tratado no campo da Educação em Ciências?

A perspectiva decolonial, defendida por Quijano, constitui-se numa abordagem que traz uma série de desafios para os/as pesquisadores/as em Educação em Ciências. Isso, ao colocar no centro do debate o questionamento dos sentidos da modernidade que foram elaborados pela historiografia canônica e seus reflexos na estruturação das bases da ciência; bem como a urgência de se empreender uma "justiça cognitiva" no campo da Educação em Ciências que, para além de seus aspectos sociais, visa a contribuir para que sejam reparados os silenciamentos e os apagamentos produzidos pela epistemologia hegemônica. De outro lado, a abordagem teórica de Butler, cuja entrada no campo tem sido bem mais tímida, mas que também tem apresentado sinais de inserção, sobretudo nos trabalhos e pesquisas focadas nas questões de gênero e sexualidade (Nascimento, \& Gouvêa, 2020). Tem revelado um pensamento afinado com as condições sociais e políticas mais prementes, dialogando com diversas correntes de pensamento e tratando de questões tais como o racismo institucional, a violência do Estado, a crítica ao Estado de Israel no trato com as populações palestinas, 
a produção de corpos precários em decorrência do avanço da lógica neoliberal entre outros.

\section{Percurso Metodológico}

O artigo decorre de uma pesquisa bibliográfica por meio da qual se realiza um trânsito pelas principais ideias elencadas tanto em Butler quanto em Quijano. O texto apresenta um recorte epistemológico focado nos conceitos de "colonialidade", "marcos de inteligibilidade" e "precariedade" por meio dos quais é possível pensar os processos de produção não só de corpos e subjetividades consideradas menos humanas, mas também a inferiorização ou apagamento de saberes ao longo do processo de consolidação da racionalidade científica ocidental (GROSFOGUEL, 2016). Num outro momento, apresenta uma discussão sobre o modo como esses dois autores se articulam a partir da análise de três obras recentemente publicadas e que dialogam com a decolonialidade na Educação em Ciências. Esse material é lido e interpretado à luz das discussões que vem sendo realizadas não apenas no campo das Ciências Sociais stricto sensu, mas de modo especial no próprio campo da Educação em Ciências e que tem como desafio pensar e repensar as condições nas quais o conhecimento científico é gerado, rompendo com as leituras de perfil positivista para as quais deve haver uma separação rigorosa entre o sujeito/observador e o objeto/observado.

Toda interpretação aqui apresentada carrega parte da subjetividade e dos olhares e experiências de pesquisa e leitura dos autores deste texto, posto ser impossível a separação entre sujeito e objeto de conhecimento, conhecimento e subjetividade. Um dos pressupostos que sustentam a análise aqui apresentada é a de que a produção do conhecimento não se dá num espaço asséptico e higienizado de conceitos e valores, mas, pelo contrário, carrega os vestígios e fragmentos de seus autores, num espaço marcado por relações de poder. O conhecimento é produzido em contextos concretos de vida e deve ser alavancado pelo diálogo sustentado pela "ética 
da responsabilidade pessoal" pelo que se diz e se afirma (COLLINS, 2019; LOWY, 1998).

Nesse sentido, as leituras e interpretações construídas e aqui apresentadas vinculamse às abordagens metodológicas que reconhecem a centralidade das experiências vividas como forma de interpretação e significação da vida social, em conexão com um referencial de sustentação teórica já legitimado. Ao mesmo tempo afirma seus compromissos éticos e políticos com os direitos humanos, sem perder a sua vinculação com o necessário rigor acadêmico (KINCHELOE; BERRY, 2007).

\section{QUIJANO E A COLONIALIDADE}

O sociólogo peruano Aníbal Quijano (1928-2018) é uma das figuras centrais para se compreender a perspectiva epistemológica, ética e política conhecida como decolonidade. Trata-se de uma abordagem que tem como traço mais marcante, o fato de ter trazido a América Latina para o centro do debate acerca da formação da modernidade, posto que a ideia de colonialidade inverte a ordem de precedência histórica consolidada ao afirmar que a América inventa a Europa ao possibilitar a acumulação de capital numa escala jamais antes vista e ao reconfigurar o mundo com uma nova grade de categorias pelas quais ele passou a ser apreendido (Segato, 2014). Quijano inova ao trazer a ideia de raça para o centro da discussão acerca da formação do padrão de poder colonial e moderno (colonialidade) gestado por ocasião da conquista das Américas em 1492 e que consolidou a divisão da humanidade em diferentes raças, organizadas a partir de um critério de classificação que estabelecia lugares de inferioridade e superioridade. Por conseguinte, esse modelo de divisão e gestão da população exerceu forte influência não apenas na forma como se classificava e dividia as pessoas, mas também nos saberes e nas formas de explicação do mundo. Em outros termos, o mecanismo de classificação social, fundamentado na ideia de raça, estrutura-se a partir de duas dimensões que se retroalimentam: a ontológica e a epistêmica (MALDONADO-TORRES, 2016; QUIJANO, 2017). 
Segundo Espinosa (2015, p. 111), "a colonialidade constitui o entrelaçamento dos processos econômicos e políticos do capitalismo com os processos de subjetivação e classificação dos grupos sociais (lugar fundamental da criação do branco, do negro e do indígena)" (trad. nossa). A colonialidade coloca-se para além do colonialismo, apesar de a ele encontrar-se vinculada e, nesse sentido, Sousa Santos (2008) evidencia uma dupla distinção, a saber: o colonialismo enquanto relação política e o colonialismo enquanto mentalidade e relação social. No primeiro caso, há situações abertas de dominação política e econômica de um povo por parte de um Estado invasor. Já quanto ao colonialismo enquanto relação social é possível perceber que, a despeito do fim do colonialismo político, há a vigência de um determinado padrão de poder capitalista, moderno e eurocentrado que se insere numa arquitetura mais sofisticada e sutil, representada pela hegemonia de um determinado modo de pensamento e de subjetividades que se difundem pela quase totalidade das sociedades, lançando na escuridão formas de ser, de viver e de existir tradicionais ou não afinadas com a lógica de mercado potencializada pelo capitalismo. Ou seja, o colonialismo enquanto relação social perdura através daquilo que Quijano chamou de colonialidade (QUIJANO, 2017; SOUZA SANTOS, 2008).

Ballestrin (2013) faz um mapeamento e o resgate de partes importantes da história do que ficou conhecido como "giro decolonial", salientando que a colonialidade se expressa por meio de uma tríade: a colonialidade do poder, do saber e do ser, sendo, como já destacado, um processo fundamental para a organização do sistema-mundo colonial/moderno. Castro-Gómez (2005), por sua vez, destaca que a categoria colonialidade encontra-se numa posição chave para se entender o debate pós-colonial na América Latina. Enquanto estrutura de dominação que sobrevive ao fim do colonialismo, a colonialidade apresenta-se como uma forma de dominação permeada pela superioridade étnica/ontológica e epistêmica/epistemológica dos colonizadores do continente americano. Enquanto categoria de análise e operador 
político, ela apresenta as seguintes características: a) a dominação por meios não coercitivos que se acopla aos esforços de se eliminarem as múltiplas formas de conhecer dos colonizados, o que remete ao tema da violência epistêmica; b) a sedução dos desejos, vontades e aspirações dos subalternos, na qual o "branco" torna-se signo do acesso ao poder e aos lugares de prestígio no imaginário cultural e; c) a produção de conhecimentos pretensamente científicos, objetivos, neutros e universais. Nesse último caso, o que se tem é a incorporação do que se convencionou chamar de a "hybris do ponto zero" - pela qual o conhecimento científico/ocidental passa a ser visto acima dos condicionamentos históricos ou como uma categoria metafísica cuja existência encontra-se acima e fora do mundo e do conjunto dos pontos de vista (Castro-Gómez, 2005). É esse o ideário que se encontra na base da epistemologia moderna e do controle social e econômico do mundo. A colonialidade faz referência a um tipo hegemônico de subjetividade (o imaginário da brancura) e a um tipo hegemônico de conhecimento (a hybris do ponto zero).

De um ponto de vista epistemológico, trata-se de uma torção nos modos como até então se pensava a constituição da modernidade e o lugar da América Latina no conjunto da história mundial, cuja centralidade se dá, em grande medida, por ter sido, aqui, o espaço no qual as condições iniciais do modelo de plantation - grandes extensões territoriais conectadas com o uso de mão-de-obra escravizada - para a alavancagem do sistema-mundial se tornaram possíveis.

A Colonialidade perpassa a problemática do poder por meio da inserção de novos aportes teóricos. Se Foucault (2000) concebe o poder como uma rede de relações que se esparrama pela sociedade, Quijano (2017, p. 88) defende que à escala societal, o poder é "uma malha de relações sociais de exploração/dominação/conflito, articuladas, basicamente, em função e em torno da disputa pelo controle dos seguintes meios de existência social": o trabalho, a natureza, o sexo, a subjetividade e a autoridade coletiva. É em torno do controle desses meios de existência e seus 
produtos que as disputas pelo poder são deflagradas. Castro-Gómez (2005) pontua que a colonialidade avança o debate sobre a analítica do poder, ao colocar em cena os seguintes aspectos e rupturas em relação ao pensamento foucaultiano: a) o controle da subjetividade começa no século XVI e não no século XVIII; b) a raça é colocada numa posição central da biopolítica, constituindo-se na primeira categoria social da modernidade e, c) a ocidentalização do imaginário como dimensão do domínio (dimensão epistêmica) garantindo a reprodução incessante do capital. Nesse último caso, o que se tem é a captura das subjetividades colonizadas, subjugadas e formatadas de forma a incorporarem o ideário da brancura e da suposta superioridade branca/europeia, o que é reforçado pela destruição de todos os mecanismos de sustentação simbólica das sociedades mantidas sob o sistema de colonização.

Essa destruição deve ser compreendida à luz das modalidades de intervenção intersubjetiva postas em movimento pela empresa colonizadora. Para isso e seguindo as pistas trilhadas por Quijano, a subjetividade é fragmentada em três elementos: o imaginário social, a memória histórica e as abordagens de conhecimento. Da perspectiva de um debate acerca da colonialidade, essas três categorias ocupam posição estratégica para se compreender de que modo a colonização - para além de seus aspectos econômicos - operou, deixando marcas profundas nas formas de ser, de viver e de conhecer dos povos colonizados. São elas que irão se constituir no elemento fundamental para o avanço da colonialidade. Enquanto construção histórico-social, a memória e o imaginário coletivos passam a fazer referência aos discursos, às pessoas, aos lugares e aos acontecimentos, nos quais o europeu e suas instituições ocupam lugar de proeminência. Tudo isso em sintonia com o apagamento das perspectivas de conhecimento ou das epistemes dos povos subalternizados. Os procedimentos de desmonte simbólico se expressam por meio da instalação de monumentos públicos, imposição de formas de Estado, da religiosidade cristã hegemônica, do sistema de ensino e das diretrizes curriculares padronizadas, procedimentos que nos remetem à 
materialização das formas de intervenção na memória, no imaginário e nas perspectivas epistêmicas dos povos colonizados. Apagam-se e silenciam-se uns para que outros entrem em cena e sejam vistos. Como corolário, emerge a naturalização das relações sociais e o apagamento de seus atravessamentos históricos de poder (PALERMO, 2014).

Em outros termos, a colonialidade opera para a efetivação do apagamento ou do esquecimento das vidas, das histórias e dos saberes colonizados. Nas trilhas de Walter Benjamin (1991), o esquecimento é seletivo assim como a memória. Os monumentos da cultura, pensados enquanto expressões do que deve ser lembrado e do que deve ser esquecido, são apreendidos não apenas como resultado do trabalho ou da ação de grandes personalidades, mas à violência e à corveia. Nesse sentido, todo documento da cultura é, ao mesmo tempo, um documento ou um testemunho da barbárie, muitas vezes imperceptível e que tem no seu silêncio a sua força e o atestado da ocorrência de uma violência que se perpetua no tempo e no espaço - uma violência que operou por meio da racialização das relações sociais. Desigualdades históricas e de poder foram naturalizadas, tratadas como se fossem existências fora dos marcos da história. Identidade sociais e geopolíticas foram engendradas, surgindo desse processo os brancos, os negros, os indígenas etc, seres projetados, categorizados e hierarquizados com base em seus traços fenotípicos, que por sua vez tornaram-se as diretrizes de acesso à cidadania - abrindo um fosso que separava as chamadas "zonas de ser e de não ser" (FANON, 2008).

Uma vez desumanizados, ou seja, alocados nas posições mais baixas das hierarquias sociais, corpos foram escravizados e, na atual conjuntura, segue-se num processo ininterrupto de criação de vidas descartáveis e supérfluas, condenadas a viver em condições precárias. Por outro lado, tal como destaca Grosfoguel (2016), a estrutura da epistemologia ocidental e todo o aparato que lhe dá sustentação foi assentada não apenas sobre o genocídio, mas também sobre o epistemicídio brutal 
que ao longo dos séculos operou e continua a operar para destruir os conhecimentos e os saberes de grupos sociais considerados à margem da racionalidade ocidental processo o qual existe outra descrição em Todorov (2016).

Genocídios e epistemicídios se inserem, provavelmente, no contexto mais amplo de relação com o outro, com a alteridade, com as formas pelas quais apreende-se e significa-se a diferença. A incorporação do problema da alteridade carrega as sementes que definirão as condições pelas quais o outro - enquanto corpo e subjetividade - ou seus saberes são representados, vistos e construídos enquanto humanos ou não humanos. A colonialidade do poder opera em parceria com a colonialidade do saber e do ser, reconfigurando as relações de poder, reafirmando locais de superioridade/inferioridade e produzindo corpos, subjetividades e conhecimentos, cujas existências são válidas apenas na medida em que se revelam úteis ao processo de acumulação de capital.

\section{JUdith ButLer, MARCos de INTELIGIBILIDADE E PRECARIEDADE: DimensõES ONTO-EPISTÊMICAS}

Judith Butler nasceu em 1956, na cidade de Cleveland/Ohio, nos Estados Unidos. Tornou-se conhecida, sobretudo, como pesquisadora das questões de gênero. Apesar do lugar que essa temática ocupa no conjunto de seus trabalhos, Butler tem desbravado outras fronteiras, tomando posição em relação a diversas outras questões éticas, políticas e epistêmicas. A despeito da diversidade temática, permanece como pano de fundo a reflexão em torno da produção de corpos abjetos e precários, situação acentuada pelo avanço sistemático do neoliberalismo sobre diversas sociedades. Por isso, considerando a sua amplitude temática, a análise, limitará aos temas dos marcos de Inteligibilidade e da precariedade.

Considerada uma herdeira do pós-estruturalismo, Butler tem sido acusada de promover uma espécie de "retorno ao humano", ao, aparentemente, retomar a 
categoria do sujeito ao longo de suas intervenções - o que a colocaria em contradição frente aos postulados pós-estruturalistas. A crítica anti-humanista elaborada ao longo do século XX apresentava os seguintes aspectos que foram tidos como rompimentos em relação ao que se convencionou chamar de Filosofia do Sujeito: a) crítica a uma noção de humano que se pretende universal a qual resulta na imposição de um modelo normalizador e unificador e; b) crítica à noção de natureza ou condição humana que faria passar por natural o que decorre de uma construção histórica e contingente. Tais enunciados foram produzidos no contexto de expansão da epistemologia ocidental e da sua pretensão à neutralidade absoluta, o que acabou obscurecendo o locus de enunciação do humano ou o espaço a partir do qual esse conceito era enunciado: a matriz "eurocentrada" formada por homens, brancos, heterossexuais, ocidentais e burgueses (GOMEZ, 2018).

Gómez (2018) salienta que, em decorrência dos paradoxos internos ao antihumanismo, tem havido, nos últimos anos uma progressiva recuperação da categoria "humano". Butler estaria entre que de alguma forma retomaram esse conceito, mas a partir de uma releitura e por meio da incorporação de novos aportes. Nesse sentido, tentando desatar o nó da aparente contradição de Butler ao promover o retorno ao humano, pode-se afirmar, que em sua reflexão, mais do que uma representação ou conceito de "humano", o que se encontra são "figuras do humano", atravessadas pela multiplicidade, pela instabilidade e pela permanente não coincidência consigo mesmas. Tal deslocamento tem permitido a recuperação da centralidade da categoria "humano", sem que se abra mão da abordagem crítica inaugurada pelo antihumanismo.

Ingala (2016) destaca que em Butler aponta o "retorno do humano" e não em "retorno ao humano", o que, segundo a autora, são coisas distintas. Há algo que retorna e não um retorno a algo que havia permanecido no mesmo lugar. Assim, há 
um "humano" que retorna, mas essa volta só ocorre por exigências estratégicas de roteiro - volta porque assim se faz necessário, mas volta outro e para outro lugar.

A volta do "humano" exige a passagem pelo "não humano", conceito para o qual Butler dedicará boa parte de sua reflexão, tendo em vista as conexões e os liames que existem entre esses dois pontos. A constituição normativa do "humano" produz, como consequência, um terreno de não humanidade ou de abjeção. Ou ainda, usando uma terminologia de Fanon (2008), a criação de "zonas de ser e de não ser". Nesse contexto, emerge a discussão sobre os marcos de inteligibilidade, uma espécie de moldura moral e epistemológica, por meio da qual se delimitam as fronteiras entre o que é pensável e não pensável. A partir de uma representação artística observada numa tela, a moldura pode ser concebida como a circunscrição do que na tela deve ser olhado/visto/apreendido/captado/considerado. Ela atuaria no sentido de delimitar o campo de observação.

De um ponto de vista epistemológico, os quadros/marcos de inteligibilidade operam como uma espécie de moldura, no sentido de fazer com que o pensar, o imaginar, o conceber, não se coloquem como atividades soltas, livres e naturais, mas como formas de intervenção no mundo condicionadas/enquadradas pelos esquemas categoriais prévios que demarcam as fronteiras do que pode ou não ser concebido ou pensado. Ao assim proceder, os marcos - enquanto instâncias morais e de normatização da vida - impõem a produção “(...) simultânea de um domínio de seres abjetos, aqueles que ainda não são 'sujeitos', mas que formam o exterior constitutivo do domínio do sujeito" (BUTLER, 2019, p. 18). O marco delimita o campo de visão, mas não elimina aquilo que a ele se encontra adjacente. Apenas dentro desses contornos impostos pelos marcos morais é que se torna possível uma certa concepção do "humano" e, dessa forma, a subversão, o questionamento e a crítica a tais quadros supõem, segundo Butler, a necessidade de uma batalha ético-política e, acrescentaríamos, epistêmica, fundamental (INGALA, 2016). 
Em outros termos, o que se propõe é a necessidade de uma "subversão epistemológica", com o objetivo de relaxar a pressão coercitiva que as normas exercem sobre corpos e subjetividades, de forma que as pessoas possam viver uma vida mais vivível (BUTLER, s/d). Se somos atravessados por uma concepção de "humano" elaborada pela matriz colonial ocidental e eurocentrada, sustentada numa perspectiva racializada e generificada de perfil binário, interessa-nos ampliar, criticar e criar novas formas de pensar e sentir o "humano", de modo que uma quantidade maior de vidas possa ser abarcada por esse conceito. Só assim é possível pensar na construção de uma democracia radical.

Enfrentar a lógica dos marcos de inteligibilidade torna-se, para Butler, uma tarefa política, ética e epistemológica. A apreensão de uma vida como humana ou não dependerá das diferentes ontologias de sujeito produzidas pelos quadros de inteligibilidade.

Se certas vidas não são qualificadas como vidas ou se, desde o começo, não são concebíveis como vidas de acordo com certos enquadramentos epistemológicos, então essas vidas nunca serão vividas nem perdidas no sentido pleno dessas palavras" (BUTLER, 2015a, p. 13).

Interpelado pelas normas e pelo poder que o constitui, o "humano" volta ao campo da reflexão e da política, mas como uma categoria que não pode ser nomeada de forma definitiva. Esse "humano" ressurge em Butler acoplado a uma série de ideias que o posicionam para além dos essencialismos e dos construtivismos: relacionalidade, reconhecimento, despossessão, dependência, vulnerabilidade e precariedade. A incorporação dessas categorias ao arcabouço butleriano representa um avanço e uma ampliação em relação ao tema das relações de poder de forma a pensar as condições que atribuem ou, negam, o estatuto de humanidade a amplos segmentos sociais (INGALA, 2016).

O "humano" retorna na forma do "corpo humano", uma categoria de análise que pressupõe uma rede de relações sociais por meio das quais ele vive e se sustenta. É 
por meio de um conjunto de relações que esse corpo é definido, relações que tornam a sua vida e as suas atuações possíveis. Dessa forma, rompe-se com o paradigma do sujeito autônomo e autossuficiente da modernidade, cujo lugar passa a ser ocupado por outro ideal de vida, no qual a vulnerabilidade assume uma posição central ao ser anexada ao pensamento de Butler como uma categoria política sobre a qual é possível pensar a resistência. Trata-se, portanto, de uma ideia de vulnerabilidade concebida como força mobilizadora de corpos que reivindicam ou se articulam politicamente a partir desse lugar de precariedade. Ao analisar as manifestações públicas, Butler (2018) ressalta que os corpos, ao mesmo tempo em que revelam a sua precariedade posto que podem ser submetidos e explorados nos níveis mais elementares de suas fragilidades - nos espaços públicos e nos confrontos com os poderes do Estado e do mercado, demonstram também resistir aos mecanismos de opressão e de precarização de suas condições estruturais e simbólicas de vida. Para Butler, e Spivak (2018) corpos precários e vulneráveis se encontram sempre inseridos e saturados pelo poder e pela política. Ninguém é invulnerável à vulnerabilidade (INGALA, 2016). Corpos precários não estão fora, mas impregnados pelas redes de poder.

Assim, num debate acerca do que seria o "humano", Butler abre uma discussão de perfil epistemológico, assumindo a posição em defesa do tensionamento dessa categoria, de uma pressão exercida sobre os quadros epistemológicos e morais que delimitam as fronteiras do que seria o "humano", tomando por base sempre a condição precária e vulnerável. O eixo desloca-se de uma suposta natureza humana para o "entre", para as relações que nos constituem, ou nos negam reconhecimento. Numa inversão da pergunta deleuziana acerca de Spinoza - "O que pode um corpo?" - Butler fará um giro, perguntando "o que um corpo não pode?" A resposta: um corpo não pode ser invulnerável e autossuficiente. E é no que não pode que o corpo encontra a sua potência e a sua capacidade de resistência e de articulação ético-política. A vulnerabilidade nos impõe uma responsabilidade ética e deveria estar no centro da 
política. Butler pretende "(...) tornar visíveis, questionar e repensar as normas que determinam quais corpos merecem ser chorados, amados, desejados, protegidos, e quais ficam excluídos desse merecimento" (INGALA, 2016, p. 885. Trad. nossa).

Os corpos aos quais se negam o reconhecimento e o substantivo "humano" são corpos que se encontram às margens, nos espaços da abjeção, nas "zonas não vivíveis" e "inabitáveis", que, contraditoriamente, são densamente povoadas pelos que não alcançam o estatuto de sujeitos, os "corpos que não importam", mas que são a condição necessária para a constituição do campo da chamada "normalidade". São corpos racial e sexualmente marcados pela lógica colonial binária, a lógica do "ou é isso ou é aquilo", e que faz com que as vivências intersticiais sejam apagadas, quando não convertidas em alvo do extermínio e do aniquilamento físico. São os corpos de menos valor, as "vidas matáveis", aquelas cujo assassinato pelos poderes do Estado ou que sofrem com as precarizações dos serviços públicos são tidos como moralmente compreensíveis e justificáveis. São corpos de pessoas transgênero, corpos pretos, com algum tipo de deficiência, corpos de mulheres, de imigrantes indocumentados, de seres fantasmagóricos que vagueiam pelos campos de refugiados, são trabalhadores precarizados de todo o mundo, cujas existências pouco ou nada importam, mas que carregam a potência de colocar em questão as normas hegemônicas, artifícios da colonialidade, revelando que a vida, mesmo desprezada, se refaz e se impõe nas frestas dos espaços do poder.

\section{Encontros da ColonialidAde E dA PRECARIEDAde COM E ENSINO de CIÊNCIAS}

No contexto de uma reflexão acerca da produção de subjetividades e saberes precários, torna-se importante lembrar que a ciência, em especial a Biologia, mas não apenas, exerceu um papel central no processo de constituição discursiva de corpos considerados inferiores e menos humanos, numa aliança com os poderes do colonialismo e, por conseguinte, da colonialidade. Isso se deu no momento em que, a 
partir de um lugar que se reconhecia como científico e, portanto, autorizado, neutro e universal, instituiu-se a ideia de raça como critério de classificação e de enquadramento biopolítico da população mundial, de forma especial, naqueles espaços nos quais o poder colonial atuou de forma mais marcante e violenta. Se a ideia de raça remonta ao século XVI, o certo é que é no século XIX, com a consolidação da ciência como a instituição máxima no que se refere à produção da "verdade", que tal ideia assume contornos mais acentuados, reforçando a construção de "zonas de ser e de não ser", de humanidade e de subumanidade. (FANON, 2008; MBEMBE, 2018a; MEMMI, 2007; QUIJANO, 2017; WILLINSKY, 2004).

Nesses termos, é certo afirmar que se Quijano se refere a colonialidade que sobrevive ao fim do colonialismo, formatando as subjetividades e impactando sobre as epistemologias outras e se Butler menciona os quadros de inteligibilidade que delimitam as fronteiras do cognoscível, ao mesmo tempo em que constroem zonas do "inabitável" e do "invivível" representadas pelos corpos abjetos - o certo é que tudo isso se dá num cenário marcado pela presença e pela ação da ciência, alçada à posição de única produtora de conhecimentos válidos, e que importam. A colonialidade se mantém, em grande medida, graças à ação da ciência universal, pensada como um elemento de normalização social, ou como um constituinte dos marcos de inteligibilidade descritos por Butler.

É no reconhecimento dessa posição da ciência no contexto da colonialidade, que diversos/as pesquisadores/as em Educação em Ciências têm se mobilizado para pensar modos outros de fazer e ensinar ciências, pautados numa relação de horizontalidade, de diálogo e de respeito por outras formas de conhecer, boa parte das quais, tornada invisível ou apagada pela epistemologia hegemônica (Grosfoguel, 2016). Isso tem sido feito por meio de diversos expedientes, tais como, a escrita firme e epistemologicamente engajada (pois o político e o epistêmico são inseparáveis), a contextualização de cada saber, a libertação desses saberes da atribuição de resíduo, 
o esforço para se construir um diálogo entre os conhecimentos científicos e os conhecimentos outros, pela desnaturalização dos mecanismos de desigualdade, pela valorização dos sistemas alternativos de produção (OLIVEIRA, 2008).

Por outro lado, Butler (2015a, 2015b), ao criticar os discursos e normas que precedem, que formatam nossos corpos e nos categorizam, estabelecendo locais de normalidade/anormalidade, abre um importante caminho para que os pesquisadores em Educação em Ciências possam pensar de forma mais densa as críticas lançadas aos fundamentos epistemológicos e políticos da ciência hegemônica. Para ela, se certas vidas são merecedoras de luto e outras não, isso se deve à ação dos enquadramentos epistemológicos e políticos que modulam as percepções e os afetos quanto ao que seria uma vida e que fundamentam e estabelecem o sentido hegemônico da palavra "humano", circunscrevendo-a a um conjunto limitado de possibilidades corporais e subjetivas. Exercer uma tensão sobre esses enquadramentos emerge como possibilidade de crítica e de construção de novas linguagens e de novos sentidos, dando à vida maior leveza e mais possibilidades de existência.

Ao ampliar os olhares sobre a produção das zonas de não ser e de vidas precárias, as leituras apresentadas por Quijano e Butler sinalizam para questões social e politicamente relevantes, sobretudo, quando se considera o avanço da lógica neoliberal e dos racismos que têm produzido levas de corpos e territórios considerados descartáveis, numa produção de vidas supérfluas que em muito lembra as análises apresentadas por Arendt (1989) ao tratar dos regimes totalitários. No contexto das apropriações desses autores por parte do campo da Educação em Ciências, trata-se também de se realizar - na esteira do que vem sendo feito por diversos movimentos no mundo todo - uma série de medidas de reparação, restituição e memória no campo do conhecimento científico e das práticas pedagógicas, de forma a reconstituir-se o conceito e a vivência de um projeto comunitário de mundo. De acordo com Mbembe (2018b, p. 313 e 314): 
"Para construir este mundo que nos é comum, será preciso restituir àqueles e àquelas que foram submetidos a processos de abstração e de coisificação na história a parte de humanidade que Ihes foi roubada."

Diante da violência - genocida e epistêmica - que presidiu a formação da epistemologia moderna da qual o ensino de ciências se tornou herdeiro da ciência universal que se expressou ao longo do tempo pelo silenciamento e pelo apagamento de outros saberes e temas no contexto das diretrizes curriculares e da sala de aula, propõe-se agora um novo desafio, o de trazer à luz o que foi obscurecido, de se pensar num ensino de ciências erguido sobre bases mais horizontais capaz de dialogar com os conhecimentos tidos como insignificantes pelo discurso hegemônico. Nesses termos essa empreitada decolonial e crítica no ensino de ciências seria uma iniciativa voltada para a promoção da "justiça cognitiva".

$\mathrm{Na}$ tentativa de se pensar o modo como essas críticas e abordagens aparecem nas produções do campo foram analisadas três obras que tratam de aspectos éticos, políticos, pedagógicos e epistemológicos no ensino de ciências para além do que é colocado pela epistemologia ocidental e pelas tradições de ensino do campo. Foram organizadas algumas ponderações acerca do modo como o tema da colonialidade atravessa esses textos, apontando possibilidades de diálogo com as categorias de análise construídas por Butler e citadas acima. As obras foram escolhidas com base na relevância que ocupam, no contexto dos debates sobre decolonialidade e ensino de ciências no Brasil. Elas são o resultado de um esforço coletivo de pesquisadores/as procedentes - predominantemente - das ciências naturais, que têm assumido o compromisso de pensar as questões desse campo para além dos seus postulados e premissas canônicas.

Nesses termos, os coletivos de pesquisadores/as proponentes desse debate alinham-se - em certa medida - com as questões salientadas por Sousa Santos (2007) ao defenderem a necessidade de se pensar o conhecimento para além da "razão indolente" e os desafios de se empreender, no bojo dos direitos humanos, uma "justiça 
cognitiva" no âmbito dos seus saberes de formação acadêmica - o que representa a possibilidade de novos pensares e fazeres em sala de aula, por meio da criação de espaços outros de comunicação horizontal e respeitosa com as perspectivas de conhecimento que foram desqualificadas pela episteme hegemônica, configurando, nesse sentido, formas de restituição e reparação da memória coletiva e do imaginário social, em sintonia com as perspectivas de conhecimento subalternizadas.

Foram as seguintes as obras escolhidas para a análise: a) Conteúdos cordiais: Química humanizada para uma escola sem mordaça, organizado por Roberto Dalmo Varallo L. de Oliveira e Glória Regina Pessoa C. Queiroz; b) Descolonizando saberes: a lei 10.639/2003 no ensino de Ciências, sob a organização de Bárbara Carine Soares Pinheiro e Katemari Rosa e; c) Decolonialidades na Educação em Ciências, organizado por Bruno A. P.Monteiro, Débora S. A Dutra, Suzani Cassiani, Celso Sánchez e Roberto D. V. L Oliveira. Todas as obras foram publicadas pela Editora Livraria da Física, respectivamente nos anos de 2017, 2018 e 2019 e integram a coleção "Culturas, Direitos Humanos e Diversidades na Educação em Ciências". Nascimento, \& Gouvêa (2020) num levantamento das produções científicas publicadas nas atas do Enpec (Encontro Nacional de Pesquisa em Educação em Ciências), no grupo de trabalho intitulado "Diferença, Multiculturalismo, Interculturalidade", apontam o aumento no número de investigações sobre a decolonialidade e a interculturalidade no ensino de ciências a partir de 2017. Com isso, a publicação das obras aqui selecionadas para análise segue uma tendência em curso no campo, marcada pela incorporação de novos referenciais teóricos e metodológicos que visam ampliar e enriquecer a forma como se pensa e se opera o ensino de ciências nas salas de aula e nos processos de formação docente. A análise foi organizada a partir da leitura sistemática das obras, de suas questões centrais, dos diálogos com o referencial teórico escolhido e seus conceitoschave, das referências e propostas didáticas apresentadas, conforme o caso. 
A primeira das obras - Conteúdos cordiais - é formada por uma introdução e nove capítulos. O referencial que pauta as discussões apresentadas tem a chamada "razão cordial", elaborada pela filósofa Adela Cortina, como chave de interpretação do que se propõe discutir. À primeira vista não parece se tratar de uma obra voltada para o decolonial. Todavia, a partir da leitura e análise de seu conteúdo, fica evidente sua interface com essa temática, mesmo que por outras vias, e por duas razões: a) a obra articula duas categorias que, historicamente, foram cindidas pela racionalidade moderna ocidental: o coração (representação dos afetos, da irracionalidade, dos sentimentos e da dimensão corpórea) e a razão (vista como instância do conhecimento por excelência, da racionalidade). Essa cisão realizada pela episteme ocidental moderna, resultou na valorização dos saberes construídos a partir do padrão epistêmico ocidental (razão), pretensamente universal e neutro e na desvalorização de outras perspectivas de conhecimento e das experiências de vida como dimensões de produção dos saberes (coração); b) pelo esforço em pensar os conteúdos da Química a partir de um conjunto de experiências subalternas de grupos sociais marginalizados, considerados como não produtores de conhecimentos. São eles: as religiões de matriz africana, as quebradeiras de coco de babaçu, as populações que vivem em zonas de sacrifício ambiental, pessoas transgênero, populações pobres e vivendo em contextos de "injustiça hídrica", catadores/as de lixo etc. A obra pode ser pensada a partir de um recorte decolonial ao explorar os potenciais epistemológicos e de ensinoaprendizagem encontrados entre essas populações. Questiona, em certa medida, os processos de produção das ausências como não existências e salienta a importância de se fazer emergir para o espaço da visibilidade pública tais saberes. Não descarta os saberes da Química ocidental, mas a eles se acoplam novos conhecimentos ou formas de pensar o mundo como um meio de se enriquecer e ao mesmo tempo produzir formas de justiça cognitiva e reparação no ensino. Os textos apontam para a presença desses saberes outros no espaço da escola, mesmo que de forma invisibilizada. Lá 
estão, mas não são considerados dignos de serem trazidos ao discurso explícito ou de serem incluídos nos currículos oficiais. Isso se configura como um dos mais potentes mecanismos da colonialidade, no caso, a do saber, que por consequência, impacta a formação das subjetividades (colonialidade do ser).

Butler, diferentemente de Quijano que não é mencionado nas referências da obra, é citada em um dos artigos, no contexto de uma discussão sobre gênero. Não há uma problematização, à luz de seu pensamento, do tema da produção de corpos definidos como sendo de pouco valor. Mas, é possível concluir que um ponto de encontro com seu pensamento pode ser indicado no momento em que se articula a ideia de razão e coração como dimensões do humano, vistas como inseparáveis e por criticar, de forma implícita, a concepção de sujeito moderno concebido como autossuficiente e autônomo e ao trazer a debate versões plurais e abertas desse humano, representado, sobretudo, por conhecimentos e por corpos precários e dissidentes.

O segundo trabalho - Descolonizando os saberes - possui dez capítulos divididos em duas partes - a primeira intitulada "Historicizando a necessidade da lei 10.639/2003", e a segunda, cujo título é "Proposições didáticas para o Ensino de Ciências" é o resultado de uma atividade curricular de uma disciplina ministrada na Pós-graduação em Ensino, Filosofia e História das Ciências, da Universidade Federal da Bahia/Universidade Estadual de Feira de Santana. A dimensão decolonial do texto se apresenta, sobretudo, ao colocar sob questionamento a colonialidade do saber e do ser ao salientar que os povos africanos e afrodiaspóricos também são produtores de conhecimento, de cultura e de ciência. Sob diversos aspectos, isso representa uma "subversão política e epistemológica", graças ao tensionamento das construções históricas por meio das quais apenas os europeus são vistos como produtores de saberes relevantes. Essa visão dos europeus como hegemônicos aparece de forma marcante no espaço da sala de aula e dos currículos escolares, na medida em que se 
observa o apagamento de outras culturas como produtoras de conhecimento. A obra chama a atenção para a necessidade de se lançarem luzes sobre a história das comunidades negras e sua relação com o ensino e a ciência. A associação entre corpos considerados inferiores/produção de saberes inferiores é posta em xeque por representar uma forma de produção da não existência. Tal apagamento é apontado como vestígio da permanência da colonialidade, mesmo que esse conceito não tenha sido explorado de forma densa nos diversos artigos que compõem a obra.

Ao trabalhar com a lei 10.639/03 e com o drama da violência do racismo, os textos abrem espaço para problematizarmos, a partir de uma perspectiva butleriana, a questão dos limites da lei na garantia e na efetivação da proteção dos corpos marcados em termos raciais e de gênero. Sua argumentação conduz às seguintes indagações: O que é uma lei? A quem ela serve? Quais atores sociais atuam no sentido de colocá-la em movimento, em funcionamento? Quais relações esses atores possuem com o poder? De forma simultânea, os trabalhos ajudam a pensar o tema do "humano", ou melhor, das "figuras do humano", desse corpo humano plural e relacional, mas enquadrado em esquemas morais e políticos que dão a cada uma de suas formas um peso de valor distinto, criando zonas de habitabilidade e de inexistência, espaços de abjeção ou não. Nesses termos, corpos pretos, uma vez capturados pelo poder, herdeiro e sustentáculo da colonialidade, apresentam-se como portadores de uma vida de menos valor, uma existência exposta aos mais altos graus de violência e precariedade. A obra também apresenta dois méritos em especial: primeiro, pautar a questão sobre quem contribui para o conhecimento e para a proliferação do saber, acentuando a questão - "Como é possível que em meio a uma pluralidade de culturas e conheceres apenas uma seja vista como produtora de conhecimento?" E, em segundo lugar e que, certamente, merece ser aprofundado, em outro momento, seja o de colocar as indagações sobre a precariedade no cenário dos grandes temas das ciências naturais, num movimento de inter/transdisciplinaridade 
com potencial para mover as bases da pedagogia tradicional e suas concepções pedagógicas e curriculares. Da leitura do material fica a percepção de que decolonizar é, antes de mais nada, tensionar o estatuto do "humano", desmontando os esquemas coloniais e seus quadros de inteligibilidade que atribuíram e continuam a atribuir essa condição a um grupo seleto e delimitado de corpos e experiências subjetivas. E é exatamente isso que um ensino de ciências de corte decolonial pretende colocar em xeque, democratizando os saberes abrindo caminhos para que a democratização radical da vida seja possível.

A última obra - Decolonialidades e Educação em Ciências - constitui-se numa coletânea composta por 19 textos, divididos entre artigos teóricos, relatos de casos e propostas metodológico-pedagógicas e sinaliza para a importância das alianças acadêmicas no processo de construção crítica do conhecimento, na medida em que boa parte dos textos apresentados resulta do que vem sendo discutido e produzido por grupos de pesquisa no Brasil e na América Latina. Pensando na história desse ele foi dividido em dois momentos. Um primeiro instante que remonta ao ano de 2009, quando a professora Suzani Cassiani foi convidada pela Capes para coordenar o Programa de Qualificação Docente e Ensino de Língua Portuguesa, no Timor Leste, excolônia portuguesa na Ásia. Essa experiência de trabalho e pesquisa se acoplou a algumas reflexões que já vinham sendo realizadas pela professora e seu grupo de pesquisas, na Universidade Federal de Santa Catarina, acerca da necessidade de se promover e implementar uma educação em ciências afinada com as necessidades e particularidades da América Latina. Segundo ela mesma informa no livro, nascia aí "o nosso giro decolonial". E um segundo instante, em 2017, durante o Enpec, foi realizada uma reunião - sob a organização da professora Suzani, com pesquisadoras e pesquisadores e a professora Maria Paula Meneses, que culminou na consolidação da organização e publicação de um livro, sobre o tema decolonialidade na Educação em Ciências. 
Mesmo quando não citada explicitamente em alguns artigos, a colonialidade permeia todos os textos, sendo, portanto, uma categoria chave para o entendimento do que é discutido. Dos 19 artigos, Quijano é citado em dez. A obra aborda a questão da produção de corpos e subjetividades subalternas e descartáveis, mas, a despeito de trabalhar com autores/as ocidentais ou de formação eurocêntrica, não apresenta a discussão a partir do que vem sendo proposto por Butler ao desenvolver sua reflexão sobre a vulnerabilidade e a resistência. Parece que a não apropriação desse referencial como suporte para as reflexões no campo da Educação em Ciências deve-se ao desconhecimento quanto às suas propostas teórico-metodológicas, na medida em que pesquisadores/as do campo já vêm dialogando com autores/as com os quais Butler tem mantido um significativo intercâmbio de ideias. Seguindo as trilhas analíticas mais críticas, os textos destacam a historicidade da Educação em Ciências, alinhavada com o processo de formação da modernidade ocidental. As abordagens e indicações de caminhos que possam se contrapor à colonialidade são mantidas, predominantemente, no campo micro, o que requer um aprofundamento acerca das questões decoloniais em macro cenários políticos mais complexos e desafiadores, representados pelo avanço de discursos autoritários sobre a agenda política e, por conseguinte, educacional. A despeito da importância de se pensar o decolonial nas práticas pedagógicas e nas brechas de resistências no cotidiano, há que se pensar como lidar com os desafios de ordem macro que ameaçam uma agenda social e política centrada nas pessoas, na vida, numa educação ampliada que reconheça a existência de conhecimentos também entre os subalternos, ou seja, entre aqueles que - de acordo com a episteme hegemônica - nada tem a ensinar.

\section{CONSIDERAÇÕES FINAIS}

Conceitos como "colonialidade", "marcos de inteligibilidade" e "precariedade" podem se constituir em importantes ferramentas para a construção de alternativas 
que possam ser contrapostas aos saberes hegemônicos. A colonialidade chama a atenção para a forma como os mecanismos de dominação se imiscuem no poder, nos saberes e na constituição das subjetividades. Os marcos morais delimitam as fronteiras do que pode ser pensado, do que pode ser reconhecido. A precariedade traz à luz o fato de que se todos estão submetidos a uma condição precária, tal condição pode ser potencializada pela ausência de mecanismos de apoio social e pela desigual atribuição de valor à vida, em decorrência da ação das normas e dos quadros de inteligibilidade que pautam os olhares e sentimentos.

Os racismos, as violências perpetradas contra pretos, pessoas transgênero, pessoas com deficiências, indígenas e outros segmentos sociais representam um passado que insiste em se fazer presente, reproduzindo desigualdades e abusos que sinalizam para o fato de que ainda não conseguimos superar a grande maioria das mazelas sociais e humanas. Esse é o desafio colocado para a Educação em Ciências decolonial, o desafio de pensar formas de se inserir nesse cenário por meio de medidas propositivas, reconhecendo as alianças entre conhecimento e poder, conhecimento e violência, conhecimento e emancipação social.

Se se faz necessário pensar formas de intervenção na realidade da escola que primem pela decolonização de saberes e fazeres, isso precisa ser feito em sintonia com uma reflexão acerca das disputas em torno da autoridade coletiva e dos problemas produzidos pela possibilidade de avanço de modelos pedagógicos ainda mais tecnicistas e "despolitizantes". Sendo o Estado um dos pilares de sustentação da colonialidade, refletir sobre os sentidos dessa instituição se faz mais do que necessário, posto que o endurecimento de suas relações com a sociedade tende a aprofundar os efeitos da colonialidade do poder sobre o conjunto da vida coletiva. Contraditoriamente, a crise dos modelos tradicionais de representação política (modelos que são expressões da colonialidade) afeta, sob vários aspectos, o futuro de uma escola mais democrática e de uma pedagogia decolonial. Mesmo sem uma 
pretensão de institucionalização nos moldes convencionais, pensar uma pedagogia decolonial impõe o desafio de se ampliar o escopo de análise sobre o Estado, a autoridade coletiva, as políticas públicas e os avanços autoritários sobre a agenda pública. Requer a formação de alianças capazes de se contrapor ao autoritarismo político e moral, que vem associado ao neoliberalismo e sua sanha contra os mecanismos de proteção social e pela reconfiguração da educação.

De certa forma, a decolonialidade no ensino de ciências vem dando sinais de inserção mais ativa e política na vida pública ao questionar o ensino conteudista e fragmentado. Também não se trata de um movimento solto, mas que se acopla à nova dinâmica social desencadeada pelos movimentos sociais e que tem representado avanços não apenas no que diz respeito ao direito de ser, mas também ao direito de saber-se, o direito à memória.

O desprendimento necessário ao estilo decolonial de viver e o tensionamento dos quadros de inteligibilidade não implicam a destruição dos saberes acumulados pela ciência ocidental moderna, mas a busca de um ponto no qual não haja mais diferentes valorações das vidas e, tampouco, a desqualificação das experiências e conhecimentos não ocidentais. Trata-se, pelo contrário, de um processo de restituição da dignidade e da pluralidade humana, uma utopia que se mantém viva porque é próprio do humano a consciência do inacabamento e a busca pelo ser mais. Sem essa dimensão de esperança e de utopia, perdemos o mais profundo da nossa condição, a nossa própria humanidade. E é para isso que uma Educação em Ciências mais crítica tem tentado nos alertar. 


\section{REFERÊNCIAS}

ARENDT, Hannah. Origens do Totalitarismo: anti-semitismo, imperialismo e totalitarismo. São Paulo: Companhia das Letras, 1989.

ARROYO, Miguel. Currículo, território em disputa. Petrópolis: Editora Vozes, 2013.

BALLESTRIN, Luciana. América Latina e o giro decolonial. Revista Brasileira de Ciência Política, Brasília, n. 11., maio - agosto de 2013, p. 89-117. https://doi.org/10.1590/S0103-33522013000200004.

BENJAMIN, Walter. Walter Benjamin: sociologia. São Paulo: Editora Ática, 1991.

BUTLER, Judith. Quadros de guerra: quando a vida é passível de luto? Rio de Janeiro: Civilização Brasileira, 2015a.

BUTLER, Judith. Relatar a si mesmo: crítica da violência ética. Belo Horizonte: Editora Autêntica, 2015b.

BUTLER, Judith. Corpos em aliança e a política das ruas: notas para uma teoria performativa de assembleia. Rio de Janeiro: Civilização Brasileira, 2018.

BUTLER, Judith; SPIVAK, Gayatri. Quem canta o Estado-Nação? Língua, política, pertencimento. Brasília: Editora da UnB, 2018.

BUTLER, Judith. Vida precária: os poderes do luto e da violência. Belo Horizonte: Editora Autêntica, 2019.

BUTLER, Judith. Repensar la vulnerabilidade y la resistência. In XV Simposio de la Asociación Internacional de Filósofas, Universidad de Alcalá/Instituto Franklin UAH/Asociación Internacional de Filósofas (IAPh), junho, 2014, Alcalá. Anais... Alcalá: universidade de Alcalá, 2014

CASTRO-GÓMEZ, Santiago. La poscolonialidad explicada a los niños. Popayán: Universidad del Cauca, 2005.

COLLINS, Patrícia Hill. Epistemologia feminista negra. In: BERNARDINO-COSTA, Joaze; MALDONADO-TORRES, Nelson; GROSFOGUEL, Ramon (orgs), Decolonialidade $e$ pensamento afrodiaspórico. Belo Horizonte: Autêntica, 2019.

ESPINOSA, Sebastián. Identidad y otredad en la teoria descolonial de Aníbal Quijano. Ciência Política, v. 10, n. 20, pp. 107-130, 2015.

FANON, Frantz. Pele negra, máscaras brancas. Salvador: Edufba, 2008.

FOUCAULT, Michel. Microfísica do poder. Rio de Janeiro: Editora Graal, 2000.

FREIRE, Paulo. Pedagogia da autonomia: saberes necessários à prática educativa. Rio de Janeiro: Paz e Terra Editora, 2019.

FREIRE, Paulo. Pedagogia do oprimido. Rio de Janeiro: Paz e Terra Editora, 2002. 
GÓMEZ, Emma Ingala. Figuras de lo humano em Judith Butler. Ideas y Valores, Bogotá/Colômbia, v. LXVIII, n. 168, pp.151-176, 2018.

GROSFOGUEL, Ramon. A estrutura do conhecimento nas universidades ocidentalizadas: racismo/sexismo epistêmico e os quatro genocídios/epistemicídios do longo século XVI. Sociedade e Estado, Brasília, v. 31, n. 1, pp. 25-49, abril, 2016. http://dx.doi.org/10.1590/S0102-69922016000100003.

INGALA, Emma. Cuerpos vulnerables y vidas precárias: ¿Un retorno de lo humano en la filosofía política de Judith Butler? Daimon. Revista Internacional de Filosofia. Suplemento 5, pp. 879-887, 2016.

KINCHELOE, Joe L; BERRY, Kathleen S. Pesquisa em educação: conceituando a bricolagem. Porto Alegre: Artes Médicas, 2007.

LÖWY, Michael. As aventuras de Karl Marx contra o Barão de Münchhausen: marxismo e positivismo na sociologia do conhecimento. São Paulo: Editora Cortez, 1998.

MALDONADO-TORRES, Nelson. Transdisciplinaridade e decolonialidade. Revista Sociedade e Estado, v. 31, n. 1, p. 75/97, jan/abr 2016,. Disponível em: http://dx.doi.org/10.1590/S0102-69922016000100005.

MBEMBE, Achille. Necropolítica. São Paulo: N-1 Edições, 2018a.

MBEMBE, Achille. Crítica da razão negra. São Paulo: N-1 Edições, 2018b.

MEMMI, Albert. Retrato do colonizado precedido de retrato do colonizador. Rio de Janeiro: Civilização Brasileira, 2007.

MONTEIRO, Bruno A. P. et al (orgs). Decolonialidades na Educação em Ciências. São Paulo: Editora Livraria da Física, 2019.

NASCIMENTO, Hiata A.; GOUVÊA, Guaracira. Diversidade, Multiculturalismo e Educação em Ciências: Olhares a partir do Enpec. Revista Brasileira de Pesquisa em Educação em Ciências, [S. I.], v. 20, n. u, p. 469-496, 2020. DOI: 10.28976/19842686 rbpec2020u469496.

Disponível

em:

https://periodicos.ufmg.br/index.php/rbpec/article/view/19614. Acesso em: 22 jan. 2021.

OLIVEIRA, Inês Barbosa de. Boaventura e a educação. Belo Horizonte: Editora Autêntica, 2008.

OLIVEIRA, Roberto Dalmo Varallo Lima de; QUEIROZ, Glória Regina Pessoa Campelo (orgs). Conteúdos cordiais: Química humanizada para uma escola sem mordaça. São Paulo: Editora Livraria da Física, 2017.

PALERMO, Zulma (comp). Para uma pedagogia decolonial. 1 ed. Ciudad Autónoma de Buenos Aires: Del Signo, 2014. 
PINHEIRO, Bárbara Carine; ROSA, Katemari (orgs). Descolonizando saberes: a lei 10.639/2003 no ensino de ciências. São Paulo: Livraria Editora da Física, 2018.

QUIJANO, Aníbal. Colonialidad del poder, eurocentrismo y América Latina. In: PALERMO, Zulma; QUINTERO, Pablo (orgs). El desprendimiento: Aníbal Quijano - textos de fundación. Buenos Aires: Ediciones del Signo, 2014.

QUIJANO, Aníbal. Colonialidade do poder e classificação social. In: SOUSA SANTOS; MENESES (orgs). Epistemologias do sul. São Paulo: Cortez, 2017.

SEGATO, Rita. La perspectiva de la colonialidad del poder. In: PALERMO, Zulma; QUINTERO, Pablo (orgs). El desprendimiento: Aníbal Quijano - textos de fundación. Buenos Aires: Ediciones del Signo, 2014.

SOUSA SANTOS, Boaventura. Renovar a teoria crítica e reinventar a emancipação social. São Paulo: Boitempo, 2007.

SOUSA SANTOS, Boaventura. Do pós-moderno ao pós-colonial. E para além de um e outro. Revista Travessias/Revista de Ciências Sociais e Humanas, $n^{0}$ 6/7. Coimbra/Portugal: Centro de Estudos Sociais, 2008.

TODOROV, TZVETAN. A conquista da América: a questão do outro. São Paulo: Martins Fontes Editora, 2016.

WILLINSKY, John. Ciência e a origem da raça. In: LOPES, Alice Casimiro; MACEDO, Elisabeth (orgs). Currículo de Ciências em debate. Campinas/SP: Papirus, 2004. 